\title{
Abnormalities in G Protein-coupled Signal Transduction Pathways in Human Disease
}

\author{
Allen M. Spiegel, Lee S. Weinstein, and Andrew Shenker \\ Molecular Pathophysiology Branch, National Institute of Diabetes and Digestive and Kidney Diseases, \\ National Institutes of Health, Bethesda, Maryland 20892
}

\section{Introduction}

Extracellular signals as diverse as hormones, growth factors, neurotransmitters, and primary sensory stimuli (photons of light, chemical odorants) all utilize a signal transduction mechanism with certain basic features in common. Signal transduction for each of these "first messengers" occurs via a G proteincoupled pathway consisting of three distinct components: receptor, $\mathrm{G}$ protein, and effector. Our understanding of each of these components at the molecular level has advanced dramatically in the past few years. $G$ protein-coupled receptors comprise a very large superfamily with hundreds of members. More than a dozen distinct mammalian $G$ proteins have been identified. $G$ protein-coupled effectors are themselves diverse and include enzymes of "second messenger" metabolism, as well as ion channels. With increased understanding of the structure and function of components of $\mathrm{G}$ protein-coupled pathways has come recognition that defects in these components can cause human disease. Given the variety of functions subserved by $G$ protein-coupled signal transduction, it is not surprising that abnormalities in $\mathrm{G}$ protein-coupled pathways can lead to diseases with manifestations as dissimilar as blindness, hormone resistance, precocious puberty, and neoplasia.

This review focuses on the mechanisms by which abnormalities in $\mathrm{G}$ protein-mediated signal transduction cause disease. First, we present a brief overview of basic aspects of $G$ proteinmediated signal transduction. (See references 1-3 for more detailed reviews of this area. Due to space restrictions, citations of original papers are limited. The reader is directed to the reviews cited for more extensive references of original papers.) We then offer some general principles useful in predicting the consequences of various defects in signal transduction, followed by a summary of those diseases (generally of humans, but in selected cases of other animals) for which there is convincing evidence for a primary signal transduction defect as the underlying cause. Finally, we will briefly discuss some disorders for which the evidence for an underlying defect in $\mathrm{G}$ protein-coupled signal transduction is less certain, and indicate additional areas worthy of further investigation.

Address correspondence to Dr. Allen M. Spiegel, National Institute of Diabetes and Digestive and Kidney Diseases, Bldg. 10, Rm. 9N-222, Bethesda, MD 20892.

Received for publication 15 March 1993 and in revised form 25 March 1993.

The Journal of Clinical Investigation, Inc.

Volume 92, September 1993, 1119-1125

\section{Overview of signal transduction via $G$ proteins}

All $G$ protein-coupled receptors identified to date share a common structural motif in which a single polypeptide with an extracellular amino terminus and intracellular carboxy terminus is predicted to span the plasma membrane seven times (4). In general terms, the ligand-binding domain is comprised of the amino terminal segment and/or portions of the membrane-spanning domains, while the $G$ protein interaction domains involve intracellular loops (especially the third) and carboxy terminus. The $\mathrm{G}$ proteins themselves are heterotrimers localized to the inner surface of the plasma membrane, and consist of an $\alpha$ subunit that binds guanine nucleotides with high affinity and specificity, and $\beta$ and $\gamma$ subunits that form a tightly but noncovalently linked dimer. The heterotrimeric form of the $G$ protein is required for high affinity interaction with receptor. Portions of the $\alpha$ subunit, particularly the carboxy terminus, are clearly important for receptor interaction. $\alpha$ subunits have long been known to regulate effectors, but recent evidence $(2,5)$ suggests that $\beta \gamma$ dimers can also regulate effector activity in many cases. $G$ protein-regulated effectors include transmembrane proteins such as adenylyl cyclase and certain ion channels, as well as peripheral membrane proteins such as CGMP phosphodiesterase and phospholipase C- $\beta$. Unlike $G$ protein-coupled receptors, there is no overall structural motif common to all $G$ protein-regulated effectors.

All $G$ protein-coupled pathways are regulated by a GTPase cycle (Fig. 1). In the basal (inactive) state, the $G$ protein heterotrimer has GDP tightly bound to its $\alpha$ subunit. Agonist binding to receptor is thought to alter the receptor's conformation, and thereby promote $\mathrm{G}$ protein interaction. This interaction catalyzes release of bound GDP from the $\alpha$ subunit and replacement with GTP. GTP binding activates the $\alpha$ subunit and causes it to dissociate from $\beta \gamma$. Both $\alpha$ and $\beta \gamma$ are now free to interact with effectors and modulate their activity. An intrinsic GTPase activity hydrolyzes the $\gamma$ phosphate of $\alpha$ subunitbound GTP, converting it to GDP. In some cases, effectors may act like the GAPs (GTPase-activating proteins) ${ }^{1}$ associated with ras and other low molecular weight GTP-binding proteins to stimulate the GTPase activity of the $\alpha$ subunit (6). The GTPase reaction deactivates the $\alpha$ subunit and causes it to reassociate with $\beta \gamma$ to reestablish the basal state of the heterotrimer.

1. Abbreviations used in this paper: AHO, Albright hereditary dystrophy; GAPs, GTPase activating proteins; MAS, McCune-Albright syndrome; PHP, pseudohypoparathyroidism. 


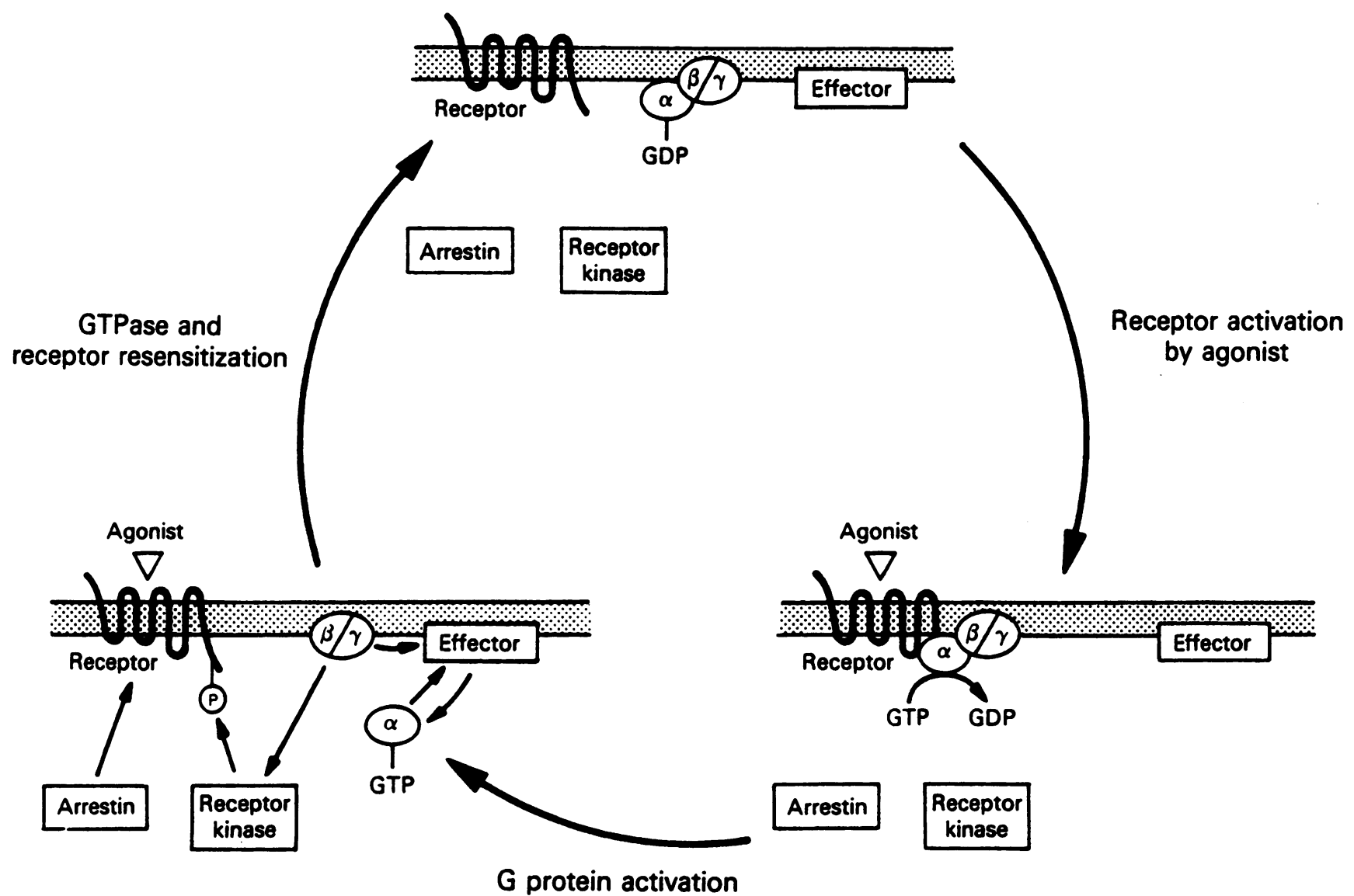

Figure 1. The G protein GTPase cycle and agonist-dependent desensitization: potential sites for disease-causing abnormalities (see text for complete description). In each panel, the stippled region denotes the plasma membrane with extracellular above and intracellular below. Arrows between $\alpha$ subunit and effector indicate regulation of effector activity by $\alpha$ subunit and regulation of $\alpha$ subunit GTPase activity by certain effectors. Receptor kinase and arrestin are shown as cytosolic proteins that translocate to the membrane upon binding to agonist-activated receptor. Arrows drawn from $\beta \gamma$ dimer denote its potential regulation of effector activity, as well as its action to facilitate membrane binding of certain receptor kinases. A presumptive receptor phosphatase (not shown) removes phosphate residues (shown here on the carboxy terminus, but may also occur on the third intracellular loop) from receptor upon resensitization.

In many $\mathrm{G}$ protein-coupled systems, prolonged exposure to agonist leads to a state of reduced responsiveness to agonist stimulation (see Fig. 1, lower left), a process termed "desensitization" (7). One mechanism of desensitization appears to involve phosphorylation of agonist-bound receptor by a receptor kinase. Phosphorylation alone may reduce coupling of receptor to $\mathrm{G}$ protein, but in addition, phosphorylation may promote binding of another protein to the receptor. Such proteins have been termed "arrestins" because of their action to arrest signal transduction, perhaps by blocking $G$ protein-receptor coupling.

$\mathrm{G}$ proteins have generally been classified by their $\alpha$ subunit. Substantial diversity in $\beta$ and $\gamma$ subunits, and the possibility of specificity in their interactions with each other and with $\alpha$ subunits offers the potential for a very large number of unique heterotrimers $(2,5)$. G proteins range in expression from highly localized (e.g., the transducins in rod and cone photoreceptors that couple rhodopsin and cone opsins, respectively, to
cGMP phosphodiesterase) to ubiquitous; e.g., Gs that couples many different receptors to stimulation of adenylyl cyclase. $G$ proteins can be grouped into subfamilies, $\mathrm{Gs}, \mathrm{Gi}, \mathrm{Gq}$, and $\mathrm{Gl}$, based on degree of amino acid conservation of their $\alpha$ subunits $(1-3,5,8)$. To some extent, these subfamilies have functional correlates in terms of receptor interaction (e.g., distinct groups of $G$ protein-coupled receptors bind to members of distinct $G$ protein subfamilies), and effector interaction (e.g., Gs stimulates adenylyl cyclase, $\mathrm{Gi}$ inhibits adenylyl cyclase, $\mathrm{Gq}$ stimulates phospholipase $\mathrm{C}-\boldsymbol{\beta}$ ). Receptor kinases and arrestins also show diversity (9), including photoreceptor-specific forms (rhodopsin kinase and the $48-\mathrm{kD}$ protein first termed arrestin) and more widely distributed forms ( $\beta$-ARKs and $\beta$-arrestins).

Abnormalities in $G$ protein-coupled signal transduction pathways in human disease: theoretical considerations In his classic description of the hormone-resistance syndrome, pseudohypoparathyroidism (PHP), Fuller Albright wrote, 
"Theoretically one should obtain essentially the same clinical picture from failure of an end-organ to respond to a hormone as from a decreased production or absence of said hormone" (10). We can now extend this concept from hormones to any extracellular first messenger. We can also state that certain defects at the end-organ level may mimic the clinical picture of first messenger excess without any primary change in first messenger production. What is the molecular basis for such changes in end-organ response? Stated most simply, receptors, $\mathrm{G}$ proteins, and effectors function like a series of "on-off" switches triggered by an extracellular signal. The GTPase activity of the $\mathrm{G}$ protein $\alpha$ subunit and the desensitization process function as timers for these on-off switches. Changes that prevent switching on any component of the pathway will cause end-organ resistance. Changes that inappropriately switch on one of the components or increase the time it spends in its "on" conformation will cause first messenger-independent hyperfunction. Table I lists some theoretical causes of decreased and increased signal transduction with examples that have been identified in human disease.

The notion that complete lack of a key signal transduction component (assuming lack of redundancy of components) would block signaling through that pathway is intuitively obvious. Less easily predicted are the consequences of reduced rather than total lack of expression or of overexpression. The consequences will depend on what factors are rate limiting in $G$ protein-coupled pathways. This issue has been addressed (11), but not definitively resolved. In terms of qualitative changes, extensive mutagenesis studies of receptors, $G$ proteins, and effectors have revealed a host of potential changes that could profoundly alter signal transduction. Restrictions of space do not permit detailed discussion of such mutations, but their identification provides insight into potential sites to be screened for mutations of signal transduction components in human disease. Loss of function mutations include those that disrupt synthesis or targeting of signal transduction components, as well as those that impair agonist binding to receptor, receptor-G protein coupling, G protein activation by GTP, or $\mathrm{G}$ protein-effector interaction (see Fig. 1). Activating mutations include those which promote agonist-independent $G$ protein activation by receptor and persistent activation of $G$ protein caused by reduced GTPase activity (Fig. 1). Defective desensitization could also impair signal transduction in several ways. Inappropriate (agonist-independent) triggering of desen-

\section{TABLE I. Theoretical Causes of Abnormal Signal Transduction with Examples in Human Disease}

\section{Decreased Signal Transduction}

1. Reduced expression of receptor, $G$ protein or effector due to defective synthesis and/or membrane targeting

Examples: -Rhodopsin mutations in retinitis pigmentosa

-V2 vasopressin receptor mutations in X-linked NDI

- Gs $\alpha$ mutations in AHO

2. Impaired activation of receptor, $G$ protein or effector

Examples: -Modification of $\mathrm{Gi} / \mathrm{Go}$ by Bordetella pertussis toxin

- Gs $\alpha$ mutation (Arg 385 to His) in AHO

3. Decrease in time that receptor, $G$ protein or effector remains in active state due to increased desensitization or GTPase activity

Example: -Decreased $\beta$-adrenergic responsiveness in cardiac failure due to increased $\beta$-ARK activity leading to increased desensitization

Increased Signal Transduction

\section{Overexpression of receptor, $G$ protein or effector}

2. Inappropriate activation of receptor, $G$ protein or effector
Example:
- Rhodopsin mutation (Lys 296 to $\mathrm{Glu}$ ) in retinitis pigmentosa

3. Increase in time that receptor, $G$ protein or effector remains in active state due to decreased desensitization or GTPase activity

Examples: -Modification of Gs by Vibrio cholera toxin

- Gs $\alpha$ mutations in sporadic pituitary and thyroid tumors and MAS

- Gi2 $\alpha$ mutations in adrenal and ovarian tumors

AHO, Albright hereditary osteodystrophy. 
sitization or inappropriately persistent desensitization could blunt end-organ response. Failure to desensitize would not necessarily cause agonist-independent signaling, but should lead to a state of supersensitivity in which agonist responsiveness is inappropriately amplified and/or persistent. Receptor mutations have been created that lead to either reduced or increased desensitization $(4,12)$. Overexpression of $\beta$-ARK or $\beta$-arrestin was shown to increase the magnitude of desensitization (13).

Many cellular responses are positively and negatively regulated by separate $\mathrm{G}$ protein-coupled pathways. For example, both hormone secretion and cell proliferation in many endocrine glands are stimulated through Gq- or Gs-coupled pathways and inhibited through $\mathrm{Gi} / \mathrm{Go}$-coupled pathways $(1,5)$. This mode of regulation of cellular response means that constitutive activation of the stimulatory pathway or loss of function of the inhibitory pathway could lead to the same abnormality in end-organ response. Hyperprolactinemia, for example, could be caused by constitutive activation of $\mathrm{Gq}$ (which mediates the stimulatory effect of TRH receptors) or by loss of function of Gi/Go (which mediates the inhibitory effect of D2 dopamine receptors). This concept is analogous to that of "dominantly" acting oncogenes vs tumor suppressor genes in the control of cell proliferation. Indeed, in the pituitary lactotroph, activated $\mathrm{Gq}-\alpha$ and inactivated $\mathrm{Gi} / \mathrm{Go}-\alpha$ could theoretically function as dominant oncogenes and tumor suppressor genes, respectively, since the receptors to which they couple regulate cell proliferation in addition to hormone secretion.

For a given defect in a $\mathrm{G}$ protein-coupled pathway, the extent of the manifestations will be determined in part by the cellular distribution of the affected component. Defects in components expressed exclusively in a single cell type (e.g., rhodopsin) will cause more of a focal disorder than defects in a widely expressed component (e.g., $\beta$-adrenergic receptor). This rule particularly applies to inherited (germline) mutations. Somatic mutations of genes encoding even a ubiquitously expressed component can cause focal disease when the somatic mutation itself is focal; i.e. expressed only in a single clonal cell population. The consequences of mutations in $\beta$-ARKs and $\beta$-arrestins will depend not only on the range of expression of these components of the desensitization process, but also on their degree of specificity. $\beta$-ARKs and $\beta$-arrestins were so named because of their demonstrated interactions with $\beta$-adrenergic receptors, but there is evidence that $\beta$-ARK can phosphorylate other $\mathrm{G}$ protein-coupled receptors (e.g., $\alpha_{2}$-adrenergic) so that multiple receptor subtypes may be regulated by the same receptor kinases and arrestins (9).

\section{Specific examples of signal transduction defects}

Receptors. Color blindness was the first disorder shown to be caused by a defective $G$ protein-coupled receptor (14). The red and green cone opsins are encoded by tandem genes on the $\mathrm{X}$ chromosome. These receptors are activated by light of a particular wave length and couple to a specialized $G$ protein, cone transducin, which modulates cGMP phosphodiesterase activity. A variety of mutations in cone opsin genes ranging from single base changes to gross deletions have been correlated with loss of color vision. Mutations in the gene encoding the corresponding photoreceptor of retinal rod cells, rhodopsin, are responsible for autosomal dominant and recessive forms of retinitis pigmentosa (15). In this disease, progressive blindness is caused by rod cell degeneration. In a family with the recessive form of the disease, a mutation causing a premature stop codon within the sequence encoding the third intra- cellular loop of rhodopsin presumptively totally prevents synthesis of receptor. Both alleles must be affected to cause clinically apparent disease. Heterozygotes for the mutation show a reduction in light responsiveness upon formal testing (16).

The autosomal dominant form of the disease has been associated with a panoply of mutations in various portions of the receptor (17). In vitro studies of mutant forms of rhodopsin indicate that many of these mutations (particularly those affecting a critical disulfide bridge linking cysteine 110 to cysteine 187) impair proper folding of the receptor, and in some cases, transport from the endoplasmic reticulum to the cell membrane. The rod cell, specialized to synthesize very large amounts of rhodopsin, is presumptively destroyed by the accumulation of abnormally folded rhodopsin. In this context, what would ordinarily be simple loss of function mutations that block response to extracellular signal, instead exert a lethal dominant effect on cell survival. A unique rhodopsin mutation in a case of dominant retinitis pigmentosa involves substitution of lysine 296 (the retinal-binding site in the seventh transmembrane domain) by glutamic acid (18). This mutation was shown to cause constitutive activation of the receptor; photoreceptor degeneration in this case may be caused by persistent stimulation of the phototransduction pathway. Interestingly, desensitization does not appear to compensate adequately for increased signal transduction by this or other ( see below) constitutively activated receptors.

In X-linked nephrogenic diabetes insipidus, loss of function mutations in the V2 vasopressin receptor (localized to chromosome Xq28 and coupled to adenylyl cyclase by Gs) cause renal resistance to the antidiuretic action of the hormone (19-23). Several of the mutations may impair formation of a putative disulfide bridge analogous to that demonstrated for rhodopsin; others cause truncation in the third intracellular loop. A missense mutation (Arg $137 \rightarrow \mathrm{His}$ ) in a residue in the second intracellular loop creates a receptor that binds vasopressin normally, but is incapable of stimulating Gs (24). Because of the hemizygous nature of the gene in males, any loss of function mutation will cause clinically evident disease.

In familial glucocorticoid deficiency caused by ACTH resistance, point mutations causing loss of function of the ACTH receptor have been found (25) (Chrousos, G., personal communication). Studies in mice provide additional examples of disorders caused by defective $G$ protein-coupled receptors. Mutations in the mouse "extension" locus cause abnormal pigmentation (26). The relevant gene encodes an MSH receptor; recessive, loss of function alleles cause hypopigmentation and correspond to a mutation causing premature truncation of the receptor between the fourth and fifth transmembrane domains. Hyperpigmentation phenotypes are caused by point mutations in the region encoding the second transmembrane domain, which lead to a constitutively activated receptor, or in the first intracellular loop, which amplify MSH responsiveness. The little mouse mutant displays dwarfism resistant to GRF but responsive to growth hormone. This phenotype is consistent with the possibility of a GRF receptor mutation (27). A common feature of all of these $G$ protein-coupled receptor diseases is the relatively localized phenotypic expression, consistent with the localized distribution of the affected receptors.

$G$ proteins. The first disease shown to be caused by defective $G$ protein function is the secretory diarrhea caused by intestinal infection with Vibrio cholerae. An exotoxin released by the bacteria catalyzes the ADP ribosylation of an arginine residue (Arg 201 in the 394 residue splice variant) of Gs- $\alpha$. This 
covalent modification inhibits GTPase activity and causes persistent Gs activation and excessive cAMP formation. The localized manifestations of the disease reflect the limited distribution of the bacteria. In vitro, cholera toxin can activate $\mathrm{Gs}$ in every cell exposed. An analogous covalent modification is catalyzed by pertussis toxin, but the substrate is a cysteine residue near the carboxy terminus of Gi- and Go- $\alpha$ subunits. This modification uncouples the $G$ protein from receptor and blocks signal transduction. The toxin's action may be relevant to some of the manifestations of pertussis infection, such as hypoglycemia.

In $\mathrm{AHO}$, affected individuals show a variety of dysmorphic features with PHP or without (pseudoPHP) associated generalized hormone resistance. In the majority of subjects with Albright hereditary osteodystrophy, membrane Gs activity is reduced by $\sim 50 \%$. Multiple distinct heterozygous mutations of the Gs- $\alpha$ gene have been identified in affected family members (28-31 ). Most mutations disrupt synthesis of mRNA and/or protein, but some missense mutations have been identified including one ( $\operatorname{Arg}^{385} \rightarrow$ His) shown to uncouple Gs from receptor $(31,32)$. A germline loss of function mutation in the ubiquitously expressed Gs- $\alpha$ gene is consistent with generalized resistance to hormones (PTH, thyroid-stimulating hormone, gonadotropins, etc.) acting via Gs-coupled receptors. How a $50 \%$ reduction in gene product causes resistance is unclear. In fact, since both subjects with pseudoPHP and PHP have mutations leading to reduced Gs activity, it appears that additional factors must determine clinical expression of hormone resistance.

About $40 \%$ of pituitary somatotroph tumors from subjects with acromegaly were shown in vitro to have constitutively activated adenylyl cyclase activity (33). All such tumors were shown to harbor somatic missense mutations in the Gs- $\alpha$ gene at either Arg 201 or Gln 227 (34, 35). As discussed earlier, Arg 201 is the site of cholera toxin modification leading to constitutive activation via reduced GTPase activity. Gln 227 is the equivalent of Gln 61, a known site of oncogenic mutation in ras. Mutations in both positions reduce GTPase activity and inappropriately prolong the time the $G$ protein spends in its active conformation. The focal nature of the somatic mutation confines the consequences, increased cAMP production with resultant growth hormone hypersecretion and increased cell proliferation, to the somatotrophs. Similar mutations have been identified in sporadic thyroid neoplasms (35).

The McCune-Albright syndrome (MAS) is a sporadic disorder in which subjects may show polyostotic fibrous dysplasia, cafe-au-lait skin pigmentation, and autonomous hyperfunction of one or more endocrine glands (gonad, adrenal cortex, thyroid, or pituitary somatotrophs). Such subjects were found to have Arg 201 missense mutations of the Gs- $\alpha$ gene in a mosaic distribution correlating with histologic evidence for $a b-$ normal cell proliferation (36). This pattern is consistent with a somatic mutation occurring early in embryologic development. Tissues harboring cells bearing the constitutively activated Gs- $\alpha$ mutant would manifest the effects of autonomously elevated cAMP production. This could readily explain the observed endocrine hyperplasia and hyperfunction, since cAMP stimulates both responses in many endocrine glands. How the Gs- $\alpha$ mutation causes pathologic changes in bone (37), skin (38), and other organs such as liver and heart (39) is not yet clear. The later in embryonic or adult development that Gs- $\alpha$ mutation occurs, the more focal the predicted manifestations. It seems likely that as in the case of acromegaly, focal somatic mutation of Gs- $\alpha$ could be the basis for diseases featuring only one manifestation of MAS; e.g. monostotic fibrous dysplasia or isolated peripheral precocious puberty. A few patients have been described with features of both PHP (renal resistance to PTH) and MAS (gonadotropin-independent precocious puberty). A missense mutation in Gs- $\alpha$ substituting a serine for a highly conserved Ala 366 was identified in two unrelated males (40). How such a mutation could lead to hormone-specific differences in responsiveness is unclear.

\section{Other disorders that may be caused by defects in $G$ protein-coupled signal transduction and future prospects}

Constitutively activating mutations of Gs- $\alpha$, as discussed earlier, may lead to benign neoplasia in cells for which increased cAMP is mitogenic. Gs- $\alpha$ mutations have not been identified in common malignancies including breast and colon (35). It is possible that constitutively activating mutations of other G- $\alpha$ subunits may be involved in benign and malignant neoplasia. Transfection of activated mutant forms of Gi2- $\alpha(41,42)$ or of Gq- $\alpha$ (43) transforms various fibroblast cell lines. The relevant second messenger pathways have not been clearly elucidated. A G12- $\alpha$ cDNA was cloned using an expression cloning strategy designed to identify novel oncogenes (44). Subsequently, constitutively activated G12- $\alpha$ has been shown to be highly oncogenic and to potentiate arachidonate release when transfected into NIH 3T3 cells (45). TSH-independent expression of Gil- $\alpha$ was found in some autonomous thyroid adenomas (46). Overexpression of $G$ protein-coupled receptors (47) (particularly those coupled to the Gq family) or transfection with constitutively activated forms of such receptors (48) also leads to cellular transformation. Activation of the gastrin-releasing peptide receptor via an autocrine loop has also been associated with small cell lung cancer (49). As yet, however, there is little evidence for naturally occurring mutations of receptor or $\mathrm{G}$ protein in human malignant tumors. Activating mutations of Gi2- $\alpha$ were identified in a minority of adrenal and ovarian tumors (35), and mas, a putative oncogene encoding a typical $\mathrm{G}$ protein-coupled receptor, was isolated from a human epidermoid carcinoma (50). There is evidence that reduced $G$ protein expression may impair normal growth and development. Inhibition of $\mathrm{Gi} 2-\alpha$ expression in liver and fat of transgenic mice (using a tissue-specific antisense construct) impaired normal growth of these organs (51).

In a variety of disorders ( see reference 1 for additional references), including tumor metastasis, diabetes mellitus, cardiac failure, and asthma $(52,53)$, there is some evidence for alterations in receptor or $\mathrm{G}$ protein signaling that may be important in pathogenesis. Much further work is needed to confirm these suggestions and to provide a molecular basis for quantitative or qualitative changes. Likewise in neuropsychiatric disorders such as alcoholism and schizophrenia (1), there have been suggestions of receptor or $G$ protein dysfunction that require additional study. The suggestion that the Alzheimer amyloid protein is a receptor coupled to Go will doubtlessly provoke further studies of Go structure and function in Alzheimer's disease (54). A recent study demonstrated reduced cAMP formation in platelets from patients with fragile $X$ syndrome (55). The relation between the gene defect and reduced cAMP formation deserves further study.

Newly appreciated functions of the $G$ protein $\beta \gamma$ dimer, such as effector regulation and $\beta$-ARK interaction, in addition to its requirement for high affinity receptor-G protein coupling make it hard to predict the consequences of alterations in $\beta \gamma$ 
structure and function. A report of a defect in the $\beta \gamma$ dimer as the cause of defective signal transduction in a mutant adrenal cell line (56) is interesting, but again, precise delineation of the molecular defect is needed. $G$ protein-regulated effector defects have not been identified in humans as yet, but a loss of function mutation of adenylyl cyclase is associated with defective "learning" in drosophila (57). In vitro biochemical studies in a patient with a phenotype identical to Gs-deficient PHP showed normal Gs function and suggested a defective adenylyl cyclase (58). Neurofibromatosis type I has been shown to be caused by mutations in a gene with homology to ras GAP (59). Given the GAP-like activity of some G protein-coupled effectors (6), effector mutations affecting the GAP activity could be envisioned as another cause of disease.

Tolerance to certain agents, notably opiates, may reflect not only desensitization, but also compensatory upregulation of other pathways. Opiates, for example, signal via Gi /Go-coupled pathways; upregulation of the Gs pathway could compensate. cAMP production is increased in cells chronically exposed to opiates $(60)$. This has led to the suggestion that the withdrawal syndrome could be caused by such upregulation of the Gs pathway (61). Enhanced cAMP formation has also been observed after chronic treatment with other agonists that signal via pertussis toxin-sensitive $G$ proteins $(62)$. It will be important to define the mechanism of such upregulation, and to determine how it contributes to the pathophysiology of addiction and withdrawal. It will also be of interest to determine more generally if defective desensitization contributes to abnormal signal transduction in certain disorders. A recent report of increased $\beta$-ARK mRNA and enzymatic activity in left ventricular samples from patients with dilated or ischemic cardiomyopathy suggests that diminished $\beta$-adrenergic responsiveness in cardiac failure may reflect not only reduced receptor number, but also increased desensitization mediated by $\beta$-ARK overexpression (63).

Finally, one should recognize that normal variation (e.g., sequence polymorphism) in signal transduction components may be associated with significant differences in signal response. The differences in color perception in individuals with a single amino acid difference in one of the cone pigment receptors is one concrete example (64). At least three polymorphic forms of the human D4 dopamine receptor, differing in the number of repeats of a 48-bp sequence within the third intracellular loop, have been identified (65). Differences in ligand binding observed for the expressed receptor variants might relate to individual differences in responsiveness to various antipsychotic drugs that bind to this dopamine receptor subtype. Polymorphism of the human $\beta_{2}$-adrenergic receptor has also been described (53). It will be fascinating to determine if variability in response to extracellular signals is generally related to such differences in signaling components.

\section{Acknowledgments}

This paper is dedicated to the memory of Gerald D. Aurbach who inspired much of our own work. We appreciate the assistance of Stephen Marx in designing the cover figure.

\section{References}

1. Spiegel, A. M., A. Shenker, and L. S. Weinstein. 1992. Receptor-effector coupling by $G$ proteins: implications for normal and abnormal signal transduction. Endocr. Rev. 13:536-565.
2. Hepler, J. R., and A. G. Gilman. 1992. G proteins. Trends Biochem. Sci. 17:383-387.

3. Conklin, B. R., and H. R. Bourne. 1993. Structural elements of $\mathrm{G} \alpha$ subunits that interact with $\mathrm{G} \beta \gamma$, receptors, and effectors. Cell. 73:631-641.

4. Dohlman, H. G., J. Thorner, M. G. Caron, and R. J. Lef kowitz. 1991 Model systems for the study of seven-transmembrane-segment receptors. Annu. Rev. Biochem. 60:653-688.

5. Birnbaumer, L. 1992. Receptor-to-effector signaling through $\mathrm{G}$ proteins: roles for $\beta \gamma$ dimers as well as $\alpha$ subunits. Cell. 71:1069-1072.

6. Bourne, H. R., and L. Stryer. 1992. G proteins. The target sets the tempo. Nature (Lond.). 358:541-543.

7. Hausdorff, W. P., M. G. Caron, and R. J. Lef kowitz. 1990, Turning off the signal: Desensitization of $\beta$-adrenergic receptor function. FASEB (Fed. Am. Soc. Exp. Biol.) J. 4:2881-2889.

8. Simon, M. I., M. P. Strathmann, and N. Gautam. 1991. Diversity of G proteins in signal transduction. Science (Wash. DC). 252:802-808.

9. Lohse, M. J., S. Andexinger, J. Pitcher, S. Trukawinski, J. Codina, J. P. Faure, M. G. Caron, and R. J. Lef kowitz. 1992. Receptor-specific desensitization with purified proteins. Kinase dependence and receptor specificity of $\beta$-arrestin and arrestin in the $\beta_{2}$-adrenergic receptor and rhodopsin systems. J. Biol. Chem. 267:8558-8564.

10. Albright, F., C. H. Burnett, P. H. Smith, and W. Parson. 1942. Pseudohypoparathyroidism: an example of "Seabright-Bantam syndrome." Endocrinology. 30:922-932.

11. Alousi, A. A., J. R. Jasper, P. A. Insel, and H. J. Motulsky. 1991. Stoichiometry of receptor- $\mathrm{G}_{\mathrm{s}}$-adenylate cyclase interactions. FASEB (Fed. Am. Soc. Exp. Biol.) J. 5:2300-2303.

12. Moffett, S., B. Mouillac, H. Bonin, and M. Bouvier. 1993. Altered phosphorylation and desensitization patterns of a human $\beta_{2}$-adrenergic receptor lacking the palmitoylated Cys341. EMBO (Eur. Mol. Biol. Organ.) J. 12:349-356.

13. Pippig, S., S. Andexinger, K. Daniel, M. Puzicha, M. G. Caron, R. J. Lef kowitz, and M. J. Lohse. 1993. Overexpression of $\beta$-arrestin and beta-adrenergic receptor kinase augment desensitization of $\beta_{2}$-adrenergic receptors. J. Biol. Chem. 268:3201-3208.

14. Nathans, J., C. M. Davenport, I. H. Maumenee, R. A. Lewis, J. F. Hejtmancik, M. Litt, E. Lovrien, R. Weleber, B. Bachynski, F. Zwas, et al. 1989. Molecular genetics of human blue cone monochromacy. Science (Wash. DC). 245:831-838.

15. McInnes, R. R., and R. A. Bascom. 1992. Retinal genetics: a nullifying effect for rhodopsin. Nature Genetics. 1:155-157.

16. Rosenfeld, P. J., G. S. Cowley, T. L. McGee, M. A. Sandberg, E. L. Berson, and T. P. Dryja. 1992. A null mutation in the rhodopsin gene causes rod photoreceptor dysfunction and autosomal recessive retinitis pigmentosa. Nature Genetics. 1:209-213.

17. Sung, C. H., B. G. Schneider, N. Agarwal, D. S. Papermaster, and J. Nathans. 1991. Functional heterogeneity of mutant rhodopsins responsible for autosomal dominant retinitis pigmentosa. Proc. Natl. Acad. Sci. USA 88:88408844.

18. Robinson, P. R., G. B. Cohen, E. A. Zhukovsky, and D. D. Oprian. 1992 Constitutively active mutants of rhodopsin. Neuron. 9:719-725.

19. Rosenthal, W., A. Seibold, A. Antaramian, M. Lonergan, M. F. Arthus, G. N. Hendy, M. Birnbaumer, and D. G. Bichet. 1992. Molecular identification of the gene responsible for congenital nephrogenic diabetes insipidus. Nature (Lond.). 359:233-235.

20. van den Ouweland, A. M. W., J. C. F. M. Dreesen, M. Verdijk, N. V. A. M. Knoers, L. A. H. Monnens, M. Rocchi, and B. A. van Oost. 1992. Mutations in the vasopressin type 2 receptor gene (AVPR2) associated with nephrogenic diabetes insipidus. Nature Genetics. 2:99-102.

21. Pan, Y., A. Metzenberg, S. Das, B. Jing, and J. Gitschier. 1992. Mutations in the V2 vasopressin receptor gene are associated with $\mathrm{X}$-linked nephrogenic diabetes insipidus. Nature Genetics. 2:103-106.

22. Merendino, J. J., Jr., A. M. Spiegel, J. D. Crawford, A. M. O'Carroll, M. J. Brownstein, and S. J. Lolait. 1993. Brief report: a mutation in the vasopressin V2-receptor gene in a kindred with X-linked nephrogenic diabetes insipidus. $N$. Engl. J. Med. 328:1538-1541.

23. Holtzman, E. J., H. W. Harris, Jr., L. F. Kolakowski, Jr., L. M. GuayWoodford, B. Botelho, and D. A. Ausiello. 1993. Brief report: a molecular defect in the vasopressin V2-receptor gene causing nephrogenic diabetes insipidus. $N$. Engl. J. Med. 328:1534-1537.

24. Rosenthal, W., A. Antaramian, S. Gilbert, and M. Birnbaumer. 1993. Nephrogenic diabetes insipidus: a V2 vasopressin receptor unable to stimulate adenylyl cyclase. J. Biol. Chem. 268:13030-13033.

25. Clark, A. J. L., A. Weber, and A. Grossman. 1993. A point mutation of the ACTH receptor in familial glucocorticoid deficiency. Pediatr. Res. 33:S14. (Abstr.)

26. Robbins, L. S., J. H. Nadeau, K. R. Johnson, M. A. Kelly, L. Roselli-Rehfuss, E. Baack, K. G. Mountjoy, and R. D. Cone. 1993. Pigmentation phenotypes of variant extension locus alleles result from point mutations which alter MSH receptor function. Cell. 72:827-834.

27. Ruvkun, G. 1992. Cell signalling. A molecular growth industry. Nature (Lond.). 360:711-712. 
28. Patten, J. L., D. R. Johns, D. Valle, C. Eil, P. A. Gruppuso, G. Steele, P. M Smallwood, and M. A. Levine. 1990. Mutation in the gene encoding the stimulatory $\mathrm{G}$ protein of adenylate cyclase in Albright's hereditary osteodystrophy. $N$. Engl. J. Med. 322:1412-1419.

29. Weinstein, L. S., P. V. Gejman, E. Friedman, T. Kadowaki, R. M. Collins E. S. Gershon, and A. M. Spiegel. 1990. Mutations of the $\mathrm{G}_{3} \alpha$-subunit gene in Albright hereditary osteodystrophy detected by denaturing gradient gel electrophoresis. Proc. Natl. Acad. Sci. USA. 87:8287-8290.

30. Weinstein, L. S., P. V. Gejman, P. De Mazancourt, N. American, and A. M. Spiegel. 1992. A heterozygous 4-bp deletion mutation in the Gs $\alpha$ gene (GNAS1) in a patient with Albright hereditary osteodystrophy. Genomics. 13:1319-1321.

31. Miric, A., J. D. Vechio, and M. A. Levine. 1993. Heterogeneous mutations in the gene encoding the $\alpha$-subunit of the stimulatory $\mathrm{G}$ protein of adenyly cyclase in Albright hereditary osteodystrophy. J. Clin. Endocrinol. \& Metab. 76:1560-1568.

32. Levine, M. A., and A. M. Spiegel. 1993. Pseudohypoparathyroidism. In Endocrinology. L. J. DeGroot, editor. W. B. Saunders Co., Philadelphia, PA

33. Vallar, L., A. Spada, and G. Giannattasio. 1987. Altered Gs and adenylate cyclase activity in human GH-secreting pituitary adenomas. Nature (Lond.) 330:566-568.

34. Landis, C. A., S. B. Masters, A. Spada, A. M. Pace, H. R. Bourne, and L. Vallar. 1989. GTPase inhibiting mutations activate the alpha chain of Gs and stimulate adenylyl cyclase in human pituitary tumours. Nature (Lond.). 340:692-696.

35. Lyons, J., C. A. Landis, G. Harsh, L. Vallar, K. Grünewald, H. Feichtinger, Q. -Y. Duh, O. H. Clark, E. Kawasaki, H. R. Bourne, et al. 1990. Two G protein oncogenes in human endocrine tumors. Science (Wash. DC). 249:655659.

36. Weinstein, L. S., A. Shenker, P. V. Gejman, M. J. Merino, E. Friedman, and A. M. Spiegel. 1991. Activating mutations of the stimulatory $G$ protein in the McCune-Albright syndrome. $N$. Engl. J. Med. 325:1688-1695.

37. Shenker, A., D. Sweet, A. M. Spiegel, and L. S. Weinstein. 1992. An activating Gs-alpha mutation is present in fibrous dysplasia of bone in the McCune-Albright syndrome. J. Bone Miner. Res. 7:S115. (Abstr.)

38. Schwindinger, W. F., C. A. Francomano, and M. A. Levine. 1992. Identification of a mutation in the gene encoding the $\alpha$ subunit of the stimulatory $G$ protein of adenylyl cyclase in McCune-Albright syndrome. Proc. Natl. Acad. Sci. USA. 89:5152-5156.

39. Shenker, A., L. S. Weinstein, A. Moran, O. H. Pescovitz, N. J. Charest, C. M. Boney, J. J. Van Wyk, M. J. Merino, P. P. Feuillan, and A. M. Spiegel. 1993. Severe endocrine and non-endocrine manifestations of the McCune-Albright syndrome associated with activating mutations of the stimulatory $\mathrm{G}$ protein, Gs. J. Pediatr. In press.

40. Nakamoto, J. M., E. A. Jones, D. Zimmerman, M. L. Scott, M. A. Donlan, and C. Van Dop. 1993. A missense mutation in the Gs-alpha gene is associated with pseudohypoparathyroidism type I-A and gonadotropin-independent precocious puberty. Clin. Res. 41:40A. (Abstr.)

41. Hermouet, S., J. J. Merendino, Jr., J. S. Gutkind, and A. M. Spiegel. 1991 Activating and inactivating mutations of the $\alpha$ subunit of $\mathrm{G}_{\mathrm{i} 2}$ protein have opposite effects on proliferation of NIH 3T3 cells. Proc. Natl. Acad. Sci. USA. 88:10455-10459.

42. Pace, A. M., Y. H. Wong, and H. R. Bourne. 1991. A mutant $\alpha$ subunit of $\mathrm{G}_{\mathrm{i} 2}$ induces neoplastic transformation of Rat-1 cells. Proc. Natl. Acad. Sci. USA. 88:7031-7035.

43. Kalinec, G., A. J. Nazarali, S. Hermouet, N. Xu, and J. S. Gutkind. 1992. Mutated $\alpha$ subunit of the $\mathrm{Gq}$ protein induces malignant transformation in NIH 3T3 cells. Mol. Cell. Biol. 12:4687-4693.

44. Chan, A. M., T. P. Fleming, E. S. McGovern, M. Chedid, T. Miki, and S. A. Aaronson. 1993. Expression cDNA cloning of a transforming gene encoding the wild-type G $\alpha 12$ gene product. Mol. Cell. Biol. 13:762-768.

45. Xu, N., L. Bradley, I. Ambudkar, and J. S. Gutkind. 1993. A mutant alpha subunit of $\mathrm{G} 12$ potentiates the eicosanoid pathway and is highly oncogenic in NIH 3T3 cells. Proc. Natl. Acad. Sci. USA. In press.
46. Selzer, E., A. Wilfing, A. Schiferer, M. Hermann, B. Grubeck-Loebenstein, and M. Freissmuth. 1993. Stimulation of human thyroid growth via the inhibitory guanine nucleotide binding $(\mathrm{G})$ protein $\mathrm{Gi}$ : constitutive expression of the G-protein $\alpha$ subunit $\mathrm{Gi}-\alpha 1$ in autonomous adenoma. Proc. Natl. Acad. Sci. USA. 90:1609-1613.

47. Julius, D., T. J. Livelli, T. M. Jessell, and R. Axel. 1989. Ectopic expression of the serotonin $1 \mathrm{c}$ receptor and the triggering of malignant transformation. Science (Wash. DC). 244:1057-1062.

48. Allen, L. F., R. J. Lef kowitz, M. G. Caron, and S. Cotecchia. 1991. G-protein-coupled receptor genes as protooncogenes: Constitutively activating mutation of the $\alpha_{1 \mathrm{~B}}$-adrenergic receptor enhances mitogenesis and tumorigenicity. Proc. Natl. Acad. Sci. USA. 88:11354-11358.

49. Corjay, M. H., D. J. Dobrzanski, J. M. Way, J. Viallet, H. Shapira, P. Worland, E. A. Sausville, and J. F. Battey. 1991. Two distinct bombesin receptor subtypes are expressed and functional in human lung carcinoma cells. J. Biol. Chem. 266:18771-18779.

50. Young, D., G. Waitches, C. Birchmeier, O. Fasano, and M. Wigler. 1986. Isolation and characterization of a new cellular oncogene encoding a protein with multiple potential transmembrane domains. Cell. 45:711-719.

51. Moxham, C. M., Y. Hod, and C. C. Malbon. 1993. Induction of Gai2-specific antisense RNA in vivo inhibits neonatal growth. Science (Wash. DC). 260:991-995.

52. Insel, P. A., and S. I. Wasserman. 1990. Asthma: a disorder of adrenergic receptors. FASEB (Fed. Am. Soc. Exp. Biol.) J. 4:2732-2736.

53. Reihsaus, E., M. Innis, N. MacIntyre, and S. B. Liggett. 1993. Mutations in the gene encoding for the $\beta_{2}$-adrenergic receptor in normal and asthmatic subjects. Am. J. Respir. Cell. Mol. Biol. 8:334-339.

54. Nishimoto, I., T. Okamoto, Y. Matsuura, S. Takahashi, Y. Murayama, and E. Ogata. 1993. Alzheimer amyloid protein precursor complexes with brain GTP-binding protein Go. Nature (Lond.). 362:75-79.

55. Berry-Kravis, E., and P. Sklena. 1993. Demonstration of abnormal cyclic AMP production in platelets from patients with fragile X syndrome. Am. J. Med. Genet. 45:81-87.

56. Mitchell, J., J. K. Northup, and B. P. Schimmer. 1992. Defective guanyl nucleotide-binding protein $\beta \gamma$ subunits in a forskolin-resistant mutant of the Y adrenocortical cell line. Proc. Natl. Acad. Sci. USA. 89:8933-8937.

57. Levin, L. R., P. -L. Han, P. M. Hwang, P. G. Feinstein, R. L. Davis, and R. R. Reed. 1992. The Drosophila learning and memory gene rutabaga encodes a $\mathrm{Ca}^{2+} /$ calmodulin-responsive adenylyl cyclase. Cell. 68:479-489.

58. Barrett, D., N. A. Breslau, M. B. Wax, P. B. Molinoff, and R. W. Downs, Jr. 1989. New form of pseudohypoparathyroidism with abnormal catalytic adenylate cyclase. Am. J. Physiol. 257:E277-E283.

59. Ballester, R., D. Marchuk, M. Boguski, A. Saulino, R. Letcher, M. Wigler, and F. Collins. 1990. The NF1 locus encodes a protein functionally related to mammalian GAP and yeast IRA proteins. Cell. 63:851-859.

60. Sharma, S. K., W. A. Klee, and M. Nirenberg. 1977. Opiate-dependent modulation of adenylate cyclase. Proc. Natl. Acad. Sci. USA 74:3365-3369.

61. Guitart, X., and E. J. Nestler. 1993. Second messenger and protein phosphorylation mechanisms underlying opiate addiction: studies in the rat locus coeruleus. Neurochem. Res. 18:5-13.

62. Thomas, J. M., and B. B. Hoffman. 1987. Adenylate cyclase supersensitivity: a general means of cellular adaptation to inhibitory agonists? Trends Pharmacol. Sci. 8:308-311.

63. Ungerer, M., M. Böhm, J. S. Elce, E. Erdmann, and M. J. Lohse. 1993. Altered expression of $\beta$-adrenergic receptor kinase and $\beta_{1}$-adrenergic receptors in the failing human heart. Circulation. 87:454-463.

64. Mollon, J. 1992. Colour vision. Worlds of difference. Nature (Lond.). 356:378-379.

65. Van Tol, H. H., C. M. Wu, H. C. Guan, K. Ohara, J. R. Bunzow, O Civelli, J. Kennedy, P. Seeman, H. B. Niznik, and V. Jovanovic. 1992. Multiple dopamine D4 receptor variants in the human population. Nature (Lond.) 358:149-152. 